\title{
Flap double twist technique for prevention of LASIK flap striae
}

\author{
This article was published in the following Dove Press journal: \\ Clinical Ophthalmology \\ 24 November 2016 \\ Number of times this article has been viewed
}

\author{
Karim Mahmoud Nabil \\ Department of Ophthalmology, \\ Faculty of Medicine, University of \\ Alexandria, Alexandria, Egypt
}

\begin{abstract}
A novel flap double twist technique was applied to reduce the incidence of postlaser-assisted in situ keratomileusis (LASIK) flap striae. The flap is floated and stroked in the same way as is done for management of first postoperative day striae, where the method is to float and irrigate the flap into position, followed by applying gentle pressure on the flap with a wet Merocel microsponge and moving the flap away from the hinge position. The sponge is then manually squeezed to become drier, and the flap is continuously stroked in a direction opposite to the hinge. Next, the flap is carefully twisted obliquely and sequentially in two opposite directions while applying gentle pressure on the flap in order to completely dehydrate the flap and stromal bed. Finally, the flap is repositioned while applying gentle horizontal pressure in two opposite directions. This novel flap double twist technique shows great success in post-LASIK striae prevention.
\end{abstract}

Keywords: laser-assisted in situ keratomileusis, wrinkles, pressure, microsponge

\section{Introduction}

Striae of the laser-assisted in situ keratomileusis (LASIK) flap are described as creases or puckers in the cornea as a consequence of LASIK surgery. ${ }^{1}$ Striae are a frequent etiological factor of post-LASIK subject dissatisfaction. Confocal microscopy shows wrinkles in the superficial corneal layers in $>97 \%$ of subjects. ${ }^{2}$ Nonetheless, the greater proportion of these subjects is asymptomatic; the incidence of clinically significant striae necessitating intervention is considerably less, ranging from $0.2 \%$ to $1.5 \%{ }^{2}$

The most frequent categorization of LASIK flap striae is according to their size. Microstriae are superficial microscopic folds and are mainly asymptomatic. They involve the basement membrane of the corneal epithelium and/or Bowman's layer. Macrostriae are full thickness larger corneal creases that frequently induce symptomatic visual deterioration and usually mandate surgical management. Other reports classify striae according to treatment; ie, whether requiring surgery or not. ${ }^{3}$

Flap striae occur as a result of slippage or wrinkling of the flap following LASIK surgery. This typically results from unbalanced realignment of the edge of the LASIK flap with the epithelial ring. It is concluded that the discrepancy in the curvature of the unchanged posterior flap and the newly altered stromal bed is the principal etiological factor for this mismatch. The modified convexity of the stromal centre can result in "flap redundancy" which is difficult to get into a perfectly flat position, described as the "tenting effect". This would clarify the greater incidence of LASIK flap striae with higher refractive errors necessitating greater depth of ablation. ${ }^{4}$

Striae are difficult to avoid. Attempts to decrease the incidence of LASIK flap striae are centered about meticulous repositioning of the flap and early examination of the flap to
Correspondence: Karim Mahmoud Nabil Department of Ophthalmology, Faculty of Medicine, University of Alexandria, Alexandria 21500, Egypt

Email karim_nabil_ophth@yahoo.com 
assure proper positioning. ${ }^{5}$ Landmarks located on the flap edge permit precise realignment of the flap. Slit lamp examination of the flap at 15 to 20 minutes postoperatively is advocated to spot early flap slippage and ensure equal distribution between the epithelial ring periphery and the flap edge. ${ }^{5}$

Regarding folds diagnosed in the early postoperative follow up, the ideal management is to float and irrigate the flap and then stretch it back into position. ${ }^{6}$ Early wrinkles can be managed by flattening with microsponges. Flattening can be undertaken under the slit lamp or under the operating microscope by gently pressing on the folds. ${ }^{7}$

Striae that fail to be flattened will require more invasive management. Many postulate the next measure is to scrape the epithelium over the folds, then irrigate the flap with balanced saline and stretch the flap back into position. ${ }^{7}$

\section{Subjects and methods}

This study was conducted on 161 eyes of 87 subjects undergoing LASIK refractive surgery for correction of myopic, hyperopic and astigmatic refractive errors using WaveLight EX500 (Alcon Laboratories; Ft Worth, TX, USA). All surgeries were performed by a single surgeon, the author. All subjects provided written informed consent for this procedure and for their data (and accompanying images if applicable) to be published in this paper. This study was approved by the Ethics Research Committee, Faculty of Medicine, University of Alexandria, Alexandria, Egypt.

A novel flap double twist technique was applied to reduce the incidence of post-LASIK flap striae. A superior hinge was applied in all cases using Moria Evolution 3 Microkeratome (Moria, Antony, France). The flap was floated and stroked in the same way as was done for management of first postoperative day striae, where the method was to float and irrigate the flap into position, followed by applying gentle pressure on the flap with a wet Merocel microsponge and moving the flap away from the hinge position. The sponge was then manually squeezed to become drier and the flap was continuously stroked in a direction opposite to the hinge.

Next, the flap was carefully twisted obliquely and sequentially in two opposite directions while gentle pressure was applied on the flap in order to completely dehydrate the flap and stromal bed (Figures 1 and 2). Finally, the flap was repositioned while applying gentle horizontal pressure in two opposite directions (Figure 3). The entire procedure was completed in 1 to 2 min, and then the flap was permitted to dry for 10 to $15 \mathrm{~s}$.

Topical steroid eye drops (1\% Econopred Plus, Alcon Laboratories, Inc., Fort Worth, TX, USA) were then instilled, making benefit of the white colored suspension to ensure gutter symmetry (Figure 4). A bandage contact

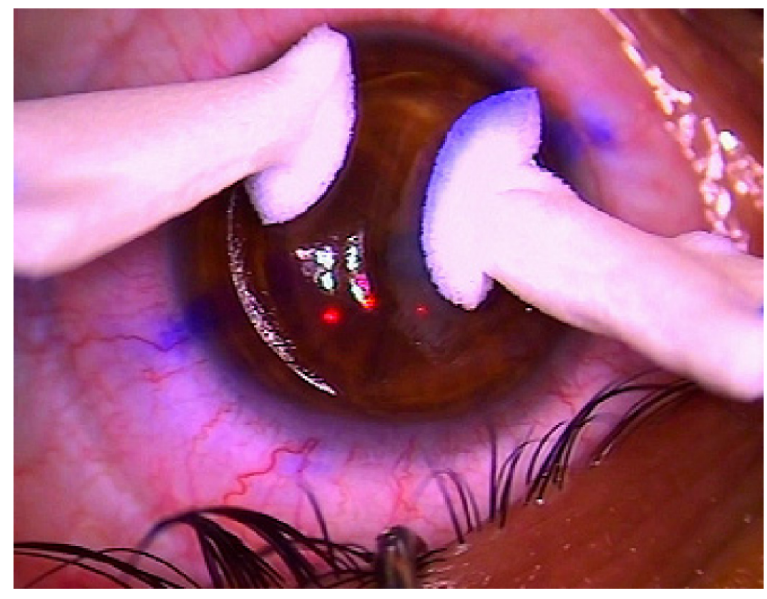

Figure I The flap was twisted obliquely while applying gentle pressure with two microsponges on the flap in order to completely dehydrate the flap and stromal bed.

lens was then applied for 24 hours. Antibiotic, nonsteroidal anti-inflammatory, and lubricating drops are applied, and the speculum was carefully removed (Video S1). Since the laser used was mounted with a slit lamp, the slit beam was passed over the corneal surface to ensure the gutter's symmetry.

The subject was then escorted to a separate slit lamp, where the gutter symmetrical width was examined again. The subject was then instructed to keep their eyes closed for 6 hours.

\section{Results}

This study was conducted on 161 eyes of 87 subjects (Table 1); 28 males (32.18\%) and 59 females (67.82\%). The mean \pm standard deviation age of the subjects was $31.59 \pm 10.32$ years. The type of refractive error was simple myopia in 19 eyes (11.80\%), myopic astigmatism in 111 eyes (68.94\%), simple hyperopia in six eyes (3.75\%), hyperopic astigmatism in 16 (9.93\%) eyes and mixed astigmatism in nine eyes (5.59\%). The spherical refractive error treated ranged from -12 to $+6 \mathrm{D}$ and

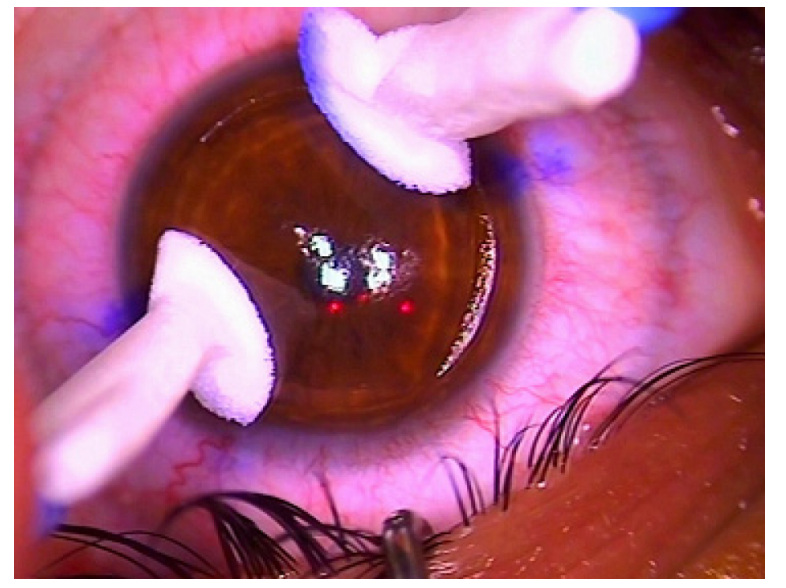

Figure 2 The flap was twisted obliquely in the opposite direction while applying gentle pressure with two microsponges on the flap. 


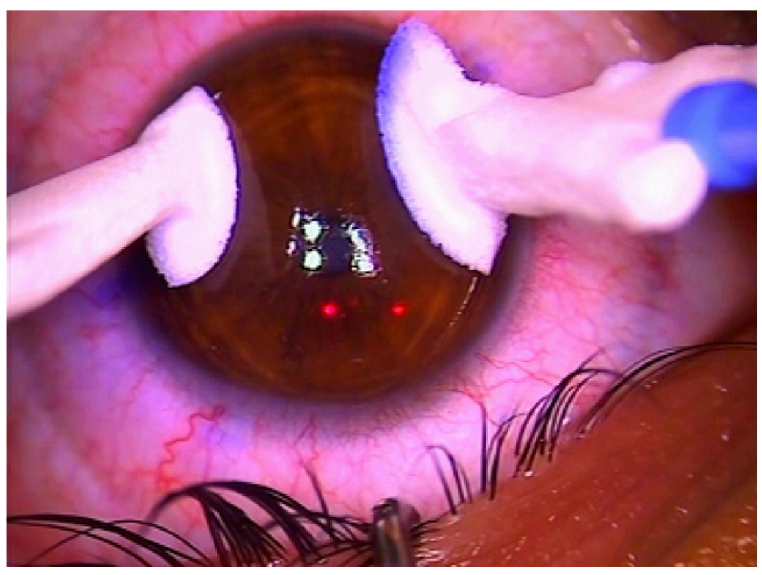

Figure 3 Repositioning the flap while applying gentle horizontal pressure in two opposite directions with two microsponges.

the astigmatic refractive error treated ranged from 0 to $-5.25 \mathrm{D}$ with the minus cylinder axis ranging from $0^{\circ}$ to $180^{\circ}$.

Corneal parameters of the studied subjects were obtained preoperatively with a Tomey anterior segment analyzer (TMS-5): K1 ranged from 39.75 to $46.06 \mathrm{D}$ with a mean of $43.03 \mathrm{D}, \mathrm{K} 2$ ranged from 40.05 to $47.61 \mathrm{D}$ with a mean of $44.21 \mathrm{D}, \mathrm{K} 1$ axis ranged from $1^{\circ}$ to $180^{\circ}$ with a mean of $75^{\circ}$ and the pachymetry of the corneal apex ranged from 496.0 to $676.0 \mu \mathrm{m}$ with a mean of $540.0 \mu \mathrm{m}$.

Regarding the operative data, the flap thickness ranged from 90 to $130 \mu \mathrm{m}$ with a mean of $110 \mu \mathrm{m}$, the ablation diameter ranged from 6.0 to $6.5 \mathrm{~mm}$ with a mean of $6.5 \mathrm{~mm}$, the ablation depth ranged from 24 to $153 \mu \mathrm{m}$ with a mean of $68 \mu \mathrm{m}$ and the residual stromal thickness ranged from 287 to $447 \mu \mathrm{m}$ with a mean of $361 \mu \mathrm{m}$ (Table 1 ).

At 1 hour, 24 hours and 1 week postoperatively, no striae were encountered in the studied subjects.

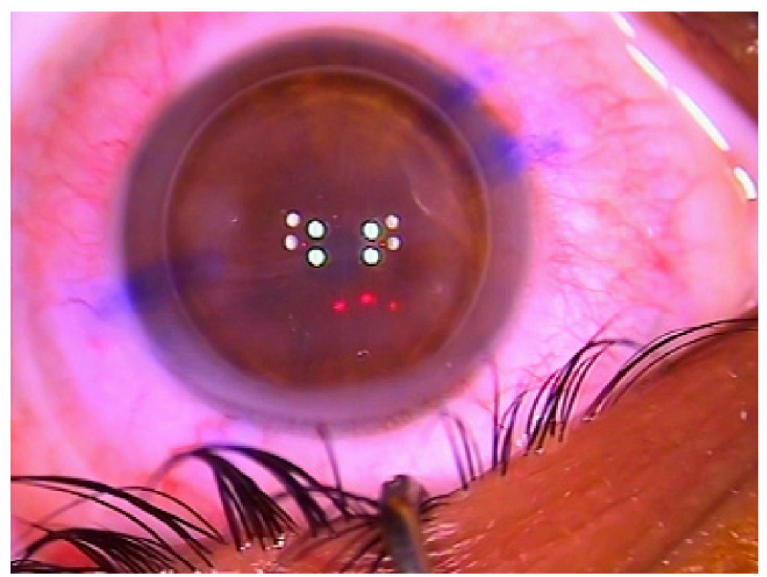

Figure 4 Topical steroid eye drops (I\% Econopred Plus, Alcon Laboratories; Ft Worth, TX, USA) are instilled making benefit of the white colored suspension to ensure gutter symmetry.
Table I Distribution of the studied cases according to different parameters

\begin{tabular}{|c|c|}
\hline Parameters & \\
\hline \multicolumn{2}{|l|}{ Sex } \\
\hline Male & $28(32.18 \%)$ \\
\hline Female & $59(67.82 \%)$ \\
\hline Age (years) & $31.59 \pm 10.32$ \\
\hline Spherical refractive error (D) & $-2.75(-12.0$ to 6.0$)$ \\
\hline Cylinder refractive error (D) & $-1.25(-5.25$ to 0.0$)$ \\
\hline Axis $\left({ }^{\circ}\right)$ & $75.0(0.0$ to 180.0$)$ \\
\hline $\mathrm{KI}(\mathrm{D})$ & 43.03 (39.75 to 46.06$)$ \\
\hline $\mathrm{K} 2(\mathrm{D})$ & $44.2 \mathrm{I}(40.05$ to $47.6 \mathrm{I})$ \\
\hline $\mathrm{KI}$ axis $\left({ }^{\circ}\right)$ & 75.0 (I.0 to 180.0$)$ \\
\hline Pachymetry apex $(\mu \mathrm{m})$ & $540.0(496.0$ to 676.0$)$ \\
\hline Ablation diameter, mm (range) & $6.50(6.0$ to 6.50$)$ \\
\hline Ablation depth $(\mu \mathrm{m})$ & $68.0(24.0$ to 153.0$)$ \\
\hline Residual thickness $(\mu \mathrm{m})$ & $361.0(287.0$ to 447.0$)$ \\
\hline Flap thickness $(\mu \mathrm{m})$ & I I 0.0 (90.0 to I30.0) \\
\hline
\end{tabular}

Note: Data shown as $\mathrm{n}(\%)$, mean \pm SD or median (interquartile range).

\section{Discussion}

Striae are a frequent etiological factor of post-LASIK subject dissatisfaction. Flap striae occur as a result of slippage or wrinkling of the flap following LASIK surgery. This typically occurs as a result of misalignment of the edge of the LASIK flap with the epithelial ring. ${ }^{4}$

Striae are difficult to prevent. Efforts to reduce the incidence of LASIK flap striae are centered around meticulous repositioning of the flap and early examination of the flap to assure proper positioning. ${ }^{5}$ Precise LASIK flap repositioning is hindered by the presence of fluid in the interface between the stromal bed and posterior flap surface, adding to the flap bed mismatch. This can be overcome by proper dehydration of this interface, as advocated in this flap double twist technique.

This novel flap double twist technique shows great success in post-LASIK striae prevention, particularly for macrostriae due to flap misplacement and dislodgment. The technique is perhaps more relevant to higher ablation of the stromal bed, specifically those with 50 to 100 micron corrections changing the convexity of the stromal bed with respect to posterior flap curvature. A question arises of whether this would apply to the more planar femtosecond flaps. As most microkeratome flaps are meniscus in profile and they are easier to lift and move, the femtosecond flaps are flimsier in the periphery compared to microkeratome flaps that are thicker in the periphery and thinner centrally. Furthermore, the femtosecond flaps have a rougher stromal bed and are harder to move temporally and nasally with a dry sponge than microkeratome flaps.

Although time consuming, this flap double twist technique can prevent one of the most common LASIK complications and does not require special instruments or learning. 


\section{Disclosure}

The author reports no conflicts of interest in this work.

\section{References}

1. Melki SA, Azar DT. LASIK complications: etiology, management and prevention. Surv Ophthalmol. 2001;46:95-116.

2. Vesaluoma M, Perez-Santonja J, Petroll WM, Linna T, Alio J, Tervo T. Corneal stromal changes induced by myopic LASIK. Invest Ophthalmol Vis Sci. 2000;41:369-376.

3. Choi CJ, Melki SA. Maddox rod effect to confirm the visual significance of laser in situ keratomileusis flap striae. J Cataract Refract Surg. 2011; 37(10):1748-1750.
4. Probst LE, Almasswary MA, Bell J. Pseudo-Fleisher ring after hyperopic laser in situ keratomileusis. J Cataract Refract Surg. 1999;25(6): 868-870.

5. Lyle WA, Jin GJ. Results of flap repositioning after laser in situ keratomileusis. J Cataract Refract Surg. 2000;26(10):1451-1457.

6. Lam DS, Leung AT, Wu JT, et al. Management of severe flap wrinkling or dislodgement after laser in situ keratomileusis. $J$ Cataract Refract Surg. 1999;25:1441-1447.

7. Jackson DW, BHamill M, Koch DD. Laser in situ keratomileusis flap suturing to treat recaltriant flap striae. J Cataract Refract Surg. 2003; 29(2):264-269.
Clinical Ophthalmology

\section{Publish your work in this journal}

Clinical Ophthalmology is an international, peer-reviewed journal covering all subspecialties within ophthalmology. Key topics include: Optometry; Visual science; Pharmacology and drug therapy in eye diseases; Basic Sciences; Primary and Secondary eye care; Patient Safety and Quality of Care Improvements. This journal is indexed on

\section{Dovepress}

PubMed Central and CAS, and is the official journal of The Society of Clinical Ophthalmology (SCO). The manuscript management system is completely online and includes a very quick and fair peer-review system, which is all easy to use. Visit http://www.dovepress.com/ testimonials.php to read real quotes from published authors. 